\title{
Breast Cancer Incidence in Diabetes Mellitus Patients on Insulin Glargine Compared with Human Neutral Protamine Hagedorn Insulin Treatment
}

\author{
Noviana Joenputri ${ }^{1}$, Nia Novianti Siregar ${ }^{2}$ \\ ${ }^{1}$ General Practitioner, Division of Hematology and Medical Oncology, Department of Internal Medicine, Dharmais Cancer Centre Hospital, \\ Jakarta, Indonesia \\ ${ }^{2}$ Internist, Division of Hematology and Medical Oncology, Department of Internal Medicine, Dharmais Cancer Centre Hospital, \\ Jakarta, Indonesia
}

\begin{abstract}
Introduction: Observational studies evaluating the association between long-acting insulins and breast cancer incidence is limited. We conducted a systematic review to compare the incidence of breast cancer between diabetes mellitus (DM) patients on longacting insulin treatment. Methodology: We systematically searched the literatures from MEDLINE, Science Direct and PROQUEST from 2008 to 2018 to identify all observational studies evaluating the relationship between use of insulin glargine and human Neutral Protamine Hagedorn (NPH) insulin to breast cancer incidence among patients with type-1 and/or type-2 diabetes mellitus (DM) aged $\geq$ 18 years old. The methodological aspects such as residual confounding and duration of follow-up were assessed. Results: A total of four cohort studies met our inclusion criteria. Follow-up duration ranged from 0.9 to 3.3 years. Two studies showed, the use of insulin glargine was associated with an increased risk of breast cancer in comparison with human NPH insulin and two other studies found no evidence of breast cancer. All of these studies had a short follow-up duration and were not able to examine residual confounding. Conclusion: We found limited support for association of glargine use with increased breast cancer risk compared to human NPH insulin due to the methodological issues. Further studies with better methodological aspects are needed to explain the difference of breast cancer incidence between those treatments.
\end{abstract}

Keywords: diabetes mellitus, insulin analog, breast cancer

\section{Introduction}

Since 1950s, NPH insulin has been widely used as treatment for type-1 and type-2 DM patients. However, it was reported that NPH insulin has disadvantage of nocturnal hipoglycemia and relatively short-half life, so it requires more frequent administration. [1,2] Because of these limitations, insulin was developed with a modified structure, known as long acting analogue insulin, one of which is insulin glargine.

Long-acting analog insulin might be associated with an increased risk of several cancers. Previous studies showed that long-acting insulin was associated with cancer cell proliferation and disrupts apoptosis because it has a higher binding affinity to insulin growth factor-1 (IGF-1) receptors. $[3,4,5]$ Breast cancer is the most prevalence cancer and the second leading cancer-related death in Indonesia. [6]

We therefore conducted a systematic review to compare the incidence of breast cancer between DM patients on insulin glargine and human NPH insulin.

\section{Methodology}

This systematic review was conducted following a prespecified protocol and reported following the Preferred Reporting Items for Systematic Reviews and Meta-Analyses (PRISMA) guidelines. [7] We systematically searched the literatures from three journal databases MEDLINE, Science Direct and PROQUEST from 2008 to 2018 to identify all observational studies evaluating the relationship between use of insulin glargine and human NPH insulin to breast cancer incidence.

We are using advanced search with keywords "diabetes mellitus" AND "insulin glargine OR insulin analogues OR human NPH insulin" AND "breast cancer". Inclusion criteria were: (1) study design cohort; (2) Study in human; (3) Article is available in English; (4) Available in full text; (5) the study was published in 2008 to 2018; (6) The outcome of the studies must be specific to breast cancer. Any studies not meeting these criteria were excluded.

\section{Results}

We found a total 1317 articles from three search engine MEDLINE, ScienceDirect, and PROQUEST. After removed duplicates, screened the title and abstract, assessed the eligibility, we found four cohort studies met our inclusion criteria. The reasons of exclusion were no human insulin as comparison (4 articles), only use glargine insulin (4 articles), study design randomized control trial (RCT) and systematic review (4 articles), and malignancy outcome not specific to breast cancer ( 1 article). The Study protocol using PRSIMA flow can be seen in Figure 1.

The study population ranged 19,337 to 115,514 patients (Table 1). The median of age ranged from 60.1 to 63.3 years. The median duration of follow up from the initiation of insulin treatment to breast cancer incidence was 0.9 to 3.3 years. The assessment of biases and methodological issue can be seen in Table 2 . 


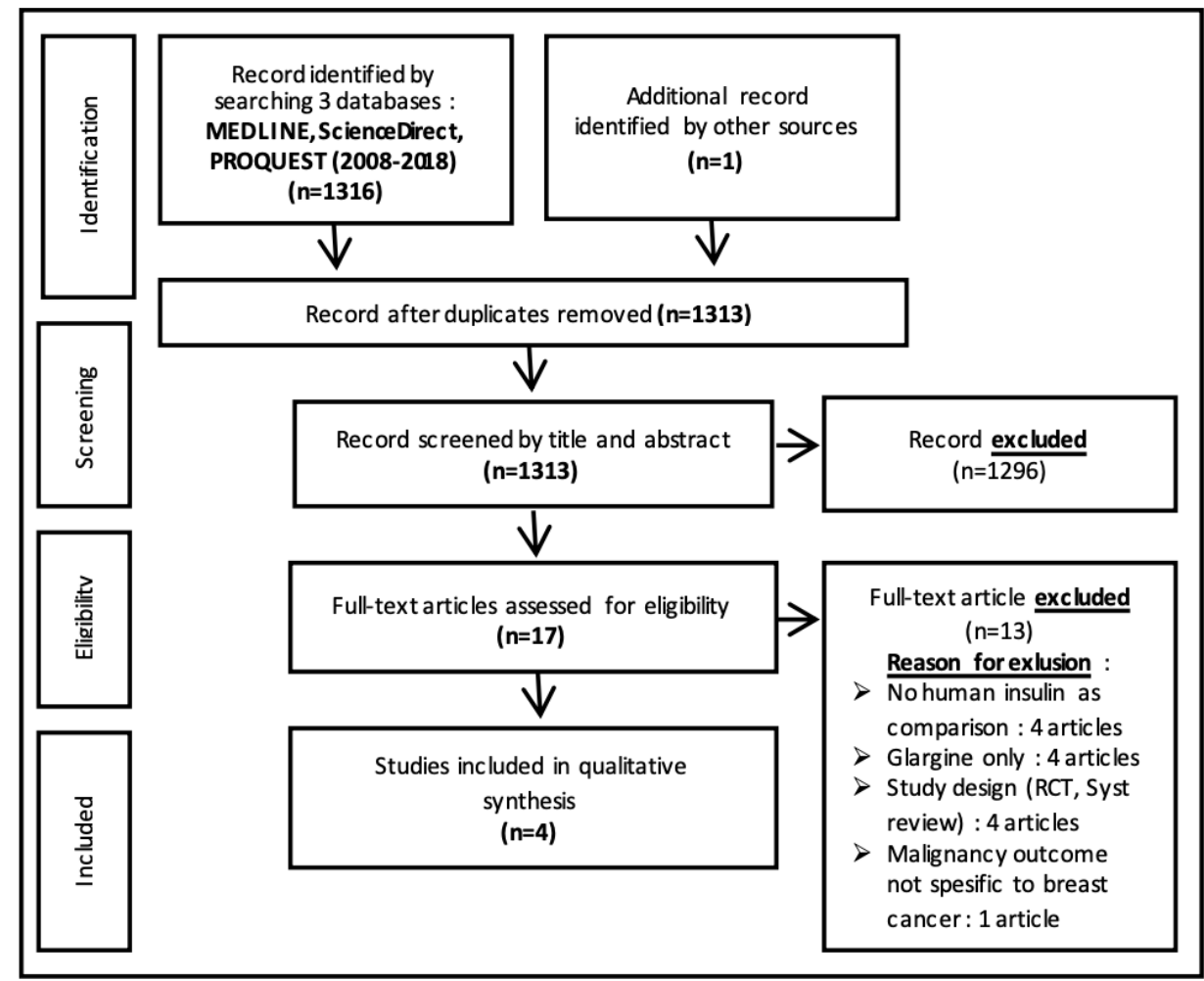

Figure 1: Protocol of this study using PRISMA flow

Table 1: Characteristic about observational studies

\begin{tabular}{|c|c|c|c|c|c|}
\hline Source & $\begin{array}{c}\text { Study } \\
\text { design }\end{array}$ & $\begin{array}{c}\text { Median } \\
\text { Follow-up } \\
\text { (years) }\end{array}$ & $\begin{array}{c}\text { Median } \\
\text { Age } \\
\text { (years) }\end{array}$ & $\begin{array}{c}\text { Study } \\
\text { sample } \\
\text { size }\end{array}$ & $\begin{array}{c}\text { Adj. Hazard Ratio } \\
\text { CI95\% }\end{array}$ \\
\hline Ruiter [8] & cohort & 3.1 & 63.3 & 19,337 & $\begin{array}{c}1.58(95 \% \mathrm{CI} \\
1.22-2.05)\end{array}$ \\
\hline Habel [9] & cohort & $\begin{array}{c}3.3(\mathrm{max} . \\
8.6)\end{array}$ & $\mathrm{n} / \mathrm{a}$ & 115,514 & $\begin{array}{c}1.60(95 \% \mathrm{CI} \\
0.90-3.10)\end{array}$ \\
\hline $\begin{array}{c}\text { Sturmer } \\
{[10]}\end{array}$ & cohort & 0.9 & 60.1 & 52,453 & $\begin{array}{c}0.67(95 \% \mathrm{CI} \\
0.18-2.54)\end{array}$ \\
\hline $\begin{array}{c}\text { Chang } \\
{[11]}\end{array}$ & cohort & 1.7 & 61.4 & 59,433 & $\begin{array}{c}0.53(95 \% \mathrm{CI} \\
0.21-1.31)\end{array}$ \\
\hline
\end{tabular}

Table 2: Assessment of biases and methodological issues

\begin{tabular}{|c|c|c|c|}
\hline Source & $\begin{array}{c}\text { Short Follow-up } \\
(<5 \text { years })\end{array}$ & $\begin{array}{c}\text { Lack of lag } \\
\text { period }\end{array}$ & $\begin{array}{c}\text { Residual } \\
\text { confounding* }\end{array}$ \\
\hline Ruiter [8] & $\bullet$ & & $\bullet$ \\
\hline Habel [9] & $\bullet$ & $\bullet$ & $\bullet$ \\
\hline Sturmer [10] & $\bullet$ & & $\bullet$ \\
\hline Chang [11] & $\bullet$ & $\bullet$ & $\bullet$ \\
\hline
\end{tabular}

Notes:

- Indicates presence of the methodological issue or bias in the study.

*Residual confounding as a result of unmeasured confounders $\left(\mathrm{HbA}_{1 \mathrm{C}}\right.$ and diabetes duration)

\section{Discussion}

We found limited studies evaluating the relationship between use of insulin glargine and human NPH insulin to breast cancer incidence. A total of four cohort studies met our inclusion criteria. All studies evaluated insulin glargine and also examined human NPH insulin. Follow-up duration ranged from 0.9 to 3.3 years.
Two studies showed, the use of insulin glargine was associated with an increase risk of breast cancer in comparison with human NPH insulin. [8,9] Ruiter et al [8] and Habel et al [9] reported the risk of breast cancer incidence in insulin glargine treatment compared with human NPH insulin was (HR 1.58, 95\%CI 1.22-2.05) [8] and (HR 1.6, 95\%CI 0.9-3.1) [9], respectively. Two other studies found no evidence that initiating DM patients with insulin glargine leads to a higher risk of breast cancer (HR 0.67, 95\%CI 0.18-2.54) [10] and (HR 0.53, 95\%CI 0.21-1.31) [11].

Potential limitations in this study including (1) We did not search the gray literature or unpublished work; (2) Search was restricted to studies published in English; (3) All of these studies had a short follow-up duration and were not able to examine residual confounding; (4) This review only focused on the association between insulin glargine, human insulin and breast cancer incidence.

\section{Conclusion}

In these studies, we found limited support for association of glargine use with increased breast cancer risk compared to human NPH insulin due to the methodological issues. Further studies with better methodological aspects are needed to explain the difference of breast cancer incidence between those treatments.

\section{References}

[1] Canadian Diabetes Association. Canadian Diabetes Association 2013 Clinical Practice Guidelines for the

\section{Volume 9 Issue 3, March 2020}




\section{International Journal of Science and Research (IJSR) \\ ISSN: 2319-7064}

ResearchGate Impact Factor (2018): 0.28 | SJIF (2018): 7.426

Prevention and Management of Diabetes in Canada. Can J Diabetes 2013; 37(Suppl. 1):1-227.

[2] National Institute for Health and Care Excellence. Type 2 diabetes: the management of type 2 diabetes [article online], 2014. Available from http://www.nice.org.uk/guidance/ cg87. Accessed 1 August 2018.

[3] Kurtzhals P , Scha ffer L, Sørensen A, et al. Correlations of receptor binding and metabolic and mitogenic potencies of insulin analogs designed for clinical use. Diabetes 2000;49:999-1005.

[4] Yehezkel E, Weinstein D, Simon M, Sarfstein R, Laron Z, Werner H. Long-acting insulin ana- logues elicit atypical signalling events mediated by the insulin receptor and insulin-like growth factor-I receptor. Diabetologia 2010;53:2667-2675

[5] Gallagher EJ, LeRoith D. Minireview: IGF, insulin, and cancer. Endocrinology 2011; 152(7):2546-51.

[6] Globocan 2018. Indonesia Fact Sheet. Assessed from https://gco.iarc.fr/today/data/factsheets/populations/360 -indonesia-fact-sheets.pdf, on 1 January 2020.

[7] Liberati A, Altman DG, Tetzlaff J, et al. The PRISMA statement for reporting systematic re- views and metaanalyses.

[8] Ruiter R, Visser LE, van Herk-Sukel MP, et al. Risk of cancer in patients on insulin glargine and other insulin analogues in comparison with those on human insulin: results from a large population-based follow-up study. Diabetologia 2012;55:51-62.

[9] Habel LA, Danforth KN, Quesenberry CP, et al. Cohort study of insulin glargine and risk of breast, prostate, and colorectal cancer among patients with diabetes. Diabetes Care 2013;36:3953-60.

[10] Sturmer T, Marquis MA, Zhou H, et al. Cancer incidence among those initiating insulin therapy with glargine versus human NPH insulin. Diabetes Care 2013;36:3517-25.

[11] Chang CH, Toh S, Lin JW, et al. Cancer risk associated with insulin glargine among adult type 2 diabetes patients-a nationwide cohort study. PLoS One 2011;6(6):e21368.1-10.

Volume 9 Issue 3, March 2020 www.ijsr.net 